\title{
Zebrafish as a prodigious tool in neuropsychiatric research
}

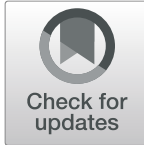

Brindha Durairaj* (D) and Madhumitha Dhanabal

\begin{abstract}
Background: The zebrafish is the system of choice in developmental biology and genetics in the recent years. Zebrafish genetics is improving, and this opens up new ways to understand genetic mechanisms. The zebrafish (Danio rerio) is used for investigation of developmental pathways and neurobiology because of its progression and physiological resemblance to humans. This species strikes stability between the sophistication as a vertebrate and its ease to be used as a model organism. In addition to this, the optical transparency of the developing fish together with novel imaging techniques enables a potent visualization of complex mechanisms at the level of the whole organism.

Methods: This review comprises information regarding zebrafish and its potent use as a model organism to study neurological disorders. The literature was collected from articles published in MEDLINE, SCOPUS, and PUBMED from 1974 to 2018.

Results: This review highlights the applications of Danio rerio in major neuropsychiatric disorders. It paves way to understand the biochemical and molecular pathways that infer in the neuropsychiatric disorders.

Conclusion: The present review discuss the significance of zebrafish as an animal model to study neurological disorders and to demonstrate the behavioural features observed which may be a precursor of a new loom for drug development.
\end{abstract}

Keywords: Danio rerio, Zebrafish, Neuropsychiatric disorders, Brain pathogenesis, Behavioural paradigm

\section{Background}

A mental disorder is a social or mental pattern that causes serious pain or loss of personal well-being, otherwise called as psychiatric disorder or dysfunctional behaviour. Such features may be persevering, relapsing, and transmitting or happen as a solitary episode. Various disorders have been depicted, with sign and indications that shift broadly between particular disorders. The root-cause of the disorder is often vague.

This analysis emphasis on the investigation of predominant human neurological disorders like anxiety, stress, schizophrenia, depression, bipolar disorder, and autism handling zebrafish as a model organism. The zebrafish is

\footnotetext{
*Correspondence: publicationbiochemistry@gmail.com; brindhavenkatesh6@gmail.com

Department of Biochemistry, PSG College of Arts \& Science, Coimbatore, Tamilnadu 641014, India
}

\section{Springer Open}

an ideal model in pharmacogenetics and neuropharmacology. Right now both larval and adult zebrafish are used to elucidate brain function, dysfunction, and their hereditary and pharmacological regulation (Kalueff, Stewart, \& Gerlai, 2014).

Being an optically transparent vertebrate, the zebrafish is physiologically homologous to Homo sapiens, allowing researchers to probe the pathways and mechanisms important to human prognosis and clinical treatment (Shin \& Fishman, 2002). Zebrafish have the majority of the established vertebrate synapses (Mueller, Vernier, \& Wullimann, 2004; Panula et al., 2006) and their neuroendocrine framework gives powerful physiological response to stress (Alsop \& Vijayan, 2008). Additionally, zebrafish are optimal model for laboratory investigation on the grounds that they are economical, low maintenance, 
rapid development, and longer lifespan (Rupert Egan et al., 2009).

Zebrafish transgenic and mutant strain paves way for knockdown and genome altering methods. This gives a unique rich toolbox to display and image the native system, concealed progress and pathology of disease (Zakaria et al., 2018). The investigations of strain differences in cerebrum capacity and drug response are made easy by the accessibility of various zebrafish strains (Kalueff et al., 2013).

\section{Development of central nervous system in zebrafish}

In the midst of gastrulation, that instigates around $6 \mathrm{hpf}$ [hours post fertilization], the zebrafish body organization is set up and cells that configure the sensory system passage to respective positions inside the developing embryo (Kimmel, Warga, \& Schilling, 1990). Correspondingly as with different vertebrates, the zebrafish central nervous system is shaped out of the neural plate, a layer of ectodermal epithelium on the dorsal side of the developing embryo. In the course of termination of gastrulation [9-10 hpf], morphogenetics intermingling developments have moulded the neural plate into a tube. Throughout the succeeding $6 \mathrm{~h}$, the neural tube is segmented into independent areas which offer ascent to the assorted cerebrum divisions.

Owing to $24 \mathrm{hpf}$, brain morphogeneis is progressed and the brain is separated into the forebrain including the diencephelon and telencephalon, midbrain, hindbrain, and spinal cord, while the earliest groups of neurons are intersected by axons (Hanneman \& Westerfield, 1989; Wilson, Ross, Parrett, \& Easter Jr., 1990). Passing through 48 hpf brain ventricles have been shaped and the zebrafish emerging embryo opens to react to external stimuli (Eisen, 1991; Jiang et al., 1996; Kawai, Arata, \& Nakayasu, 2001; Kimmel et al., 1990; Kimmel, Patterson, \& Kimmel, 1974; Raible DW, Hodsdon, Henion, Weston, \& Eisen, 1992). The glial cells subtypes, oligodendrocytes, Schwann cells, and astrocytes are found in zebrafish hatchlings from 4 dpf [days post fertilization] (Brosamle \& Halpern, 2002). The rapid improvement of the zebrafish central nervous system permits the primary useful test at $48 \mathrm{hpf}$, while further developed testing is conceivable from $4 \mathrm{dpf}$.

Limited sections in the CNS (central nervous system) of zebrafish, for example, the hypothalamus, optic tracts, olfactory system, spinal cord, and cranial nerves, validate a reasonable structural homology to the pertinent zones of the human brain, while the others indicate more articulated contrasts. Regardless of the fact that the zebrafish does not build up a layered neocortex, their cerebellum has molecular, Purkinje cell, and granule cell layers like those found in a mammalian brain, while comparable genes and specific markers are expressed too. In zebrafish cerebellum, the cell bodies of neurons are situated in the cortex, whereas in mammals, it is present in the deep nuclei (Bae et al., 2009; Ito \& Yamamoto, 2009).

A crucial measure of the mammalian brain is the development of the blood-brain barrier. This barrier is rudimentary for keeping up brain homeostasis and spillage of the barrier can prompt serious cerebrum pathologies. At that point again, its relative impermeability is additionally a noteworthy barrier in medication conveyance to the cerebrum. The blood-brain barrier penetrability is directed by the endothelial cells in the veins which are fixed by tight intersections and which comprehend particular transporter atoms and vesicles. The endothelial tight intersection based blood-brain barrier of zebrafish has appeared to be close to that of higher vertebrates and is functional at $10 \mathrm{dpf}$ (Jeong et al., 2008).

GABA, glutamate, dopamine, noradrenaline, serotonin, histamine, and acetylcholine are present in zebrafish notwithstanding the fact that there are differences in expression compared to that of mammalian frameworks. One prominent disparity of well-evolved organisms and zebrafish is that the zebrafish undergoes perpetual development and establishment of new neurons (Grandel, Kaslin, Ganz, Wenzel, \& Brand, 2006; Lam, Marz, \& Strahle, 2009; Tropepe \& Sive, 2003). In a nutshell, the CNS of zebrafish resembles the human nervous system (Celine De Esch, Slieker, Wolterbeek, Woutersen, \& de Groot, 2012).

\section{Zebrafish as a model organism for brain pathogenesis}

The improvement of zebrafish behavioural models to contemplate mental illness has gathered much intrigue, both as a model to examine ailment aetiology, and to help in the advancement of new therapeutics (Brennan, 2011; Levin., 2007; Ellis \& Soanes, 2012). In social neurobiology, zebrafish are quickly rising as another ground-breaking model between in vitro studies and mammalian in vivo look into. Larval zebrafish show simple, characterized, and stereotyped sensorimotor behaviour with open and portrayed circuitry, in this way giving a vertebrate frame amendable to vast scale forward genetics and synthetic screening (Kalueff et al., 2013; Meshalkina et al., 2017; Sisson \& Gerlai, 2010; Stewart et al., 2014; Wolman, Jain, Liss, \& Granato, 2011). Figure 1 represents the development of brain in zebrafish.

Zebrafish develop quickly, with the basic body plan spread out within $24 \mathrm{~h}$. The organs develop within the initial days of life, once the fish is just a couple of millimetres long, making measures in 96 well-plate arrangement conceivable. A single combination of grown-ups will breed once every week, turning out 100-200 eggs for each rearing. The transient hereditary qualities are controlled by microinjection of DNA, mRNA, or 


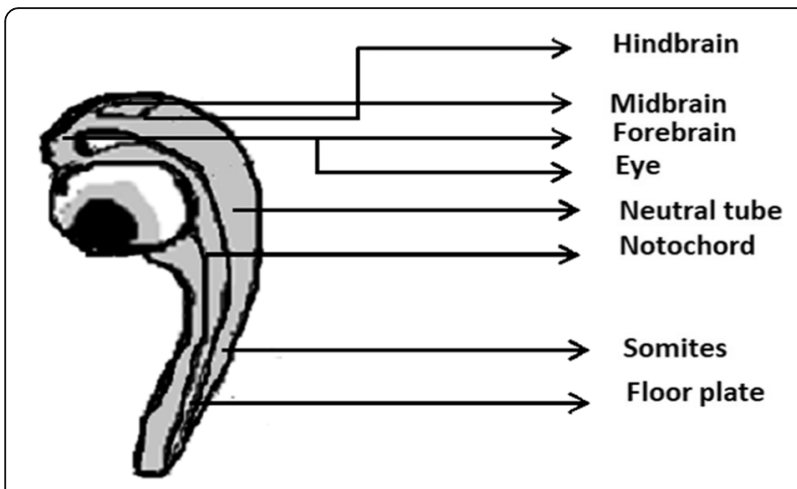

Fig. 1 Brain develops within pharyngula period (29h)

morphilinos, which are antisense DNA oligonucleuotides that can adjust protein synthesis in the growing embryo by obstructing a particular site or a splice donor or acceptor site is possible because of the advancement of ex utero studies in zebrafish (Goldsmith, 2004).
Table 1 represents the domain, criterion, and phenotype modelled in zebrafish. In addition to the above, shoal formation is a general zebrafish movement (Kalueff et al., 2013). Shoaling is best characterized as collection behaviour that prompts conspecifics being dispersed in a given region of space (e.g., a waterway) closer to one another than if there should be an occurrence of stochastic distribution (Miller \& Gerlai, 2011).

Aggression is additionally basic zebrafish behaviour, reflected in methodology, orbiting, undulating body developments, balance raise, mouth opening, head butting, gnawing, reflection pursuing, and body shading change (Kalueff et al., 2013). Numerous set up mirror presentation-based tests (e.g., level mirror measure, slanted mirror test, two level mirror examinations with various acclimation periods, a live conspecific test, a clay model stimulus assay, and a video recording test) exist for studying the aggressive behaviour of zebrafish (Way, Ruhl, Snekser, Kiesel, \& McRobert, 2015).

Table 1 Vital neuro-phenotypic domains and their behavioural paradigm in Zebrafish

\begin{tabular}{|c|c|c|c|}
\hline Disorder & Behaviour & Criterion & Zebrafish Phenotype \\
\hline \multirow[t]{3}{*}{ Stress } & Aggression & $\begin{array}{l}>\text { Live observation of two fish } \\
>\text { Mirror image test } \\
>\text { Pigment response } \\
>\text { Startle reaction }\end{array}$ & $\begin{array}{l}>\text { Reduction of exploration } \\
\triangleright \text { Increased avoidance } \\
\triangleright \text { Erratic behaviour } \\
\triangleright \text { Elevated cortisol }\end{array}$ \\
\hline & Alarm reaction & Response to alarm substance & \\
\hline & Anti-predation & Predator stimulation & \\
\hline Anxiety & $\begin{array}{l}\text { Fear related } \\
\text { behaviour }\end{array}$ & $\begin{array}{l}>\text { Exit latency test } \\
>\text { Group preference } \\
>\text { Light/dark preference } \\
>\text { Locomotor activity } \\
>\text { Thigmotaxis } \\
>\text { Tank diving test } \\
>\text { Time in enriched T-maze } \\
\text { chamber }\end{array}$ & \\
\hline Depression & \multirow[t]{2}{*}{ Locomotion } & \multirow{2}{*}{$\begin{array}{l}>\text { Mean velocity } \\
>\text { Number of lines crossed } \\
>\text { Total distance crossed } \\
>\text { Turning angle }\end{array}$} & $\begin{array}{l}\triangleright \text { Reduced activity } \\
\triangleright \text { Flevation of cortisol }\end{array}$ \\
\hline \multirow[t]{5}{*}{$\begin{array}{l}\text { Autism and } \\
\text { schizophrenia }\end{array}$} & & & Assessment of memory and learning \\
\hline & Audition & Response to startling noise & \\
\hline & Courtship & Observation of courtship postures & Potent social behaviour \\
\hline & Learning/memory & $\begin{array}{l}>\text { Active avoidance conditioning } \\
\triangleright \text { Delayed spatial alterations } \\
\triangleright \text { Learned alarm reactions } \\
>\text { Spatial alterations } \\
\triangleright \text { T-maze } \\
>\text { Visual discrimination learning }\end{array}$ & $\begin{array}{l}>\text { Hyper activity } \\
>\text { Impaired cognitive process }\end{array}$ \\
\hline & Olfaction & Response to amino acids & \\
\hline Sleep disorders & Sleep & $\begin{array}{l}\text { Monitoring sleep postures } \\
\text { Pigment response } \\
\text { Locomotor inhibition }\end{array}$ & $\begin{array}{l}>\text { Vigorous circadian rhythms } \\
>\text { Sensitive to sleep-modulating drugs }\end{array}$ \\
\hline Neurodegeneration & Locomotion & $\begin{array}{l}\text { Interaction with object } \\
\text { Total distance moved }\end{array}$ & Decline in locomotion \\
\hline $\begin{array}{l}\text { Reward-related } \\
\text { behaviour }\end{array}$ & Reward & $\begin{array}{l}\text { Conditioned place preference } \\
\text { Presence of conspecific }\end{array}$ & $\begin{array}{l}\text { Rewarding stimuli, including food and abused } \\
\text { substances }\end{array}$ \\
\hline
\end{tabular}


Anxiety/fear responses include attack, chase, chewing, coloration response, erratic movement, freeze, geotaxis, and jaw movement which are yet to be studied. Cognitive behavioural assays incorporate swimming, head butting, reproductive behaviour, territorial behaviour, and thigmotaxis. Attraction, background adaptation, scavenging, home-base formation, thrashing, tilting, and top dwelling are under the class of social behavioural assays (Kalueff et al., 2014).

\section{Zebrafish as a pharmacological eye opener}

Zebrafish are a model outline for pharmacological examinations, since compounds can be dissolved in the embryo medium, and larvae are straightforward implying that inside organs can be imaged all through advancement. Moreover, larvae are little, simple to create in huge numbers and simple to control making them perfect for high-throughput work. At the same time, since screens that utilize behaviour as a read-out are difficult to structure and actualize efficiently (especially if concentrating on complex behaviours other than locomotion), it may be simpler to complete an underlying prescreen of a sickness endo-phenotype (Peterson et al., 2000; William H.J.Norton, 2013).

Although fish are thought to have poor recollections and show couple of complex behaviours, various investigations have disproved such convictions. Table 2 depicts the disorders and its behavioural impact demonstrated in zebrafish as a key contribution to understanding the basis of behaviour (Norton \& Bally-Cuif, 2010). One of the key difficulties with CNS drug discovery is the need to seclude specific regions of the cerebrum interceding a specific issue or ailment. Treatments have turned out to be accessible for subjective weakness, despite the fact that these have been ruled by two classes of medication, acetyl cholinesterase inhibitors, and $\mathrm{N}$-methyl-D-aspartate (NMDA) antagonists.

A portion of the pharmacological medicines that have just been utilized in zebrafish are 17-ethinylestradiol which is a manufactured oestrogen that helps in decreasing aggressive behaviour. Diazepan acts as a sedative and improves the impact of the synapse gamma-aminobutyric acid (GABA) at the GABA-A receptor, bringing about sedative effect, hypnotic (sleep-inducing), anxiolytic (antianxiety), anticonvulsant, and muscle relaxant properties. Nicotinic agonist (NachR) is nicotine that mimics the activity of neurotransmitter acetylcholine.

Four other fascinating targets are phosphor-diesterase, histamine $\mathrm{H} 3$ receptors, $5 \mathrm{HT} 6$ receptors, and AMPA receptor, which are presently being explored preclinically and the efficacy of zebrafish to represent the targets (Best \& Alderton, 2008).

\section{Conclusion}

In the present review, we highlight the intensity of zebrafish to study neurological disorders at all life stages and stresses more specifically the advantage of this living being for formative brain research at an early age. Zebrafish indicate extraordinary potential as a model in cerebrum research and demonstrate a high relationship with other models and in addition with human information. Additionally, more particular behaviour test can be performed proficiently, reproducibly, and dependably at an early life juncture in zebrafish. Despite the fact that to date there have been moderately few investigations of zebrafish conduct, the simplicity of completing pharmacological examinations coupled to the regularly expanding number of accessible hereditary devices propose that zebrafish are going to enter the spotlight. The ideal organism demonstrating diseases and high-throughput screening, with physiological and hereditary homology

Table 2 Disorders and its behavioural effect modelled in zebrafish

\begin{tabular}{|c|c|c|c|}
\hline Disorder & Inducing agent & Mode of action & Outcome \\
\hline Autism & \multirow[t]{2}{*}{ MK-801 L-NAME } & NMDA antagonist & \multirow{2}{*}{$\begin{array}{l}>\text { Impaired memory } \\
>\text { Decreased shoal cohesion } \\
>\text { Decreased social preference }\end{array}$} \\
\hline Schizophrenia & & NO synthase inhibitor & \\
\hline Anxiety & Ethanol & GABA-A receptor modulator & Anti-predation impaired by high doses \\
\hline \multirow[t]{3}{*}{ Stress } & Alarm substance & Hypoxanthine-3N-oxide & \multirow[t]{3}{*}{ Increases anxiety } \\
\hline & Pentylene-tetrazole & GABA antagonist & \\
\hline & Caffeine & Xanthine alkaloid & \\
\hline \multirow[t]{2}{*}{ Sleep disorders } & Pentobarbital & Barbiturate & \multirow[t]{2}{*}{ Hypnotic } \\
\hline & Diazepam & Benzodiapine & \\
\hline \multirow[t]{4}{*}{ Reward-related behaviour } & Ethanol & GABA-A receptor modulator & \multirow[t]{4}{*}{ Rewarding } \\
\hline & Morphine & Opiate & \\
\hline & Cocaine & Psychostimulant & \\
\hline & Amphetamine & & \\
\hline
\end{tabular}


to humans, are zebrafish. These organisms demonstrate to be progressively helpful in translational brain research and are appropriate to address the developing difficulties of this field. Zebrafish offer the possibility to consolidate tests at biochemical, cell, and molecular dimension inside an individual life form in time. Moreover, concerning the 3R's (replacement, reduction, and refinement of animal experiments), fish embryo that are not feeding autonomously are considered substitution or refinement strategies. For future research, the primary test stays to find and realize the key pathways transverse over species, to eventually realize the total suitability of the zebrafish.

\section{Abbreviations}

hpf: Hours post fertilization; dpf: Days post fertilization; CNS: Central nervous system; GABA: Gamma-aminobutyric acid; NMDA: N-methyl-D-aspartate receptor

\section{Acknowledgements}

We would like to express our sincere thanks to our institution PSG College of Arts and Science, Coimbatore, Tamilnadu, India, for their valuable guidance and support.

\section{Authors' contributions}

Corresponding author (Brindha Durairaj): Framework, guidance, and support. Author (Madhumitha Dhanabal): Data collection and manuscript writing. The authors read and approved the final manuscript.

\section{Funding}

Nil

\section{Availability of data and materials \\ Not applicable}

Ethics approval and consent to participate

Not applicable

\section{Consent for publication}

No

\section{Competing interests}

The authors declare that they have no competing interests.

Received: 8 August 2019 Accepted: 10 August 2020

Published online: 27 August 2020

\section{References}

Alsop, D., \& Vijayan, M. M. (2008). Development of the corticosteroid stress axis and receptor expression in zebrafish. Am J PhysiolRegullntegr Comp Physiol, 294, 711-719. https://doi.org/10.1152/ajpregu.00671.2007.

Bae, Y. K., Kani, S., Shimizy, T., Tanabe, K., Nojima, H., Kimura, Y., et al. (2009). Anatomy of zebrafish cerebellum and screening for mutations affecting its development. Developmental Biology, 330, 406-426. https://doi.org/10.1016/j. ydbio.2009.04.013.

Best, J. D., \& Alderton, W. K. (2008). Zebrafish: An in vivo model for the study of neurological diseases. Neuropsychiatric Disease and Treatment, 4(3), 567-576. https://doi.org/10.2147/ndt.s2056.

Brennan, C. H. (2011). Zebrafish behavioural assays of translational relevance for the study of psychiatric disease. Reviews in the Neurosciences, 22, 37-48. https://doi.org/10.1515/RNS.2011.006.

Brosamle C, Halpern ME. (2002). Characterization of myelination in the developing zebrafish. Glia, 39, 47-57. doi: org/https://doi.org/10.1002/glia.10088

De Esch, C., Slieker, R., Wolterbeek, A., Woutersen, R., \& De Groot, D. (2012). Zebrafish as potential model for developmental neurotoxicity testing: A mini review. Neurotoxicity and Teratology., 34(6), 545-453. https://doi.org/10.1016/j. ntt.2012.08.006

Egan, R. J., Bergner, C. L., Hart, P. C., Cachat, J. M., Canavello, P. R., Elegante, M. F., .. Mohnot (2009). Understanding behavioural and physiological phenotypes of stress and anxiety in zebrafish. Behavioural Brain Research, 205(1), 38-44. https://doi.org/10.1016/j.bbr.2009.06.022.

Eisen, J. S. (1991). Developmental neurobiology of the zebrafish. The Journal of Neuroscience, 11, 311-317.

Ellis, L. D., \& Soanes, K. H. (2012). A larval zebrafish model of bipolar disorder as a screening platform for neuro-therapeutics. Behavioural Brain Research, 233(2), 450-457. https://doi.org/10.1016/j.bbr.2012.05.043.

Goldsmith, P. (2004). Zebrafish as a pharmacological tool: The how, why and when. Current Opinion in Pharmacology, 4(5), 504-512. https://doi.org/10 1016/j.coph.2004.04.005.

Grandel, H., Kaslin, J., Ganz, J., Wenzel, I., \& Brand, M. (2006). Neural stem cells and neurogenesis in the adult zebrafish brain: Origin, proliferation dynamics, migration and cell fate. Developmental Biology, 295, 263-277.

Hanneman, E., \& Westerfield, M. (1989). Early expression of acetylcholinesterase activity in functionally distinct neurons of the zebrafish. The Journal of Comparative Neurology, 284, 350-361. https://doi.org/10.1002/cne.902840303.

Ito, H., \& Yamamoto, N. (2009). Non-laminar cerebral cortex in teleost fishes? Biology Letters, 5, 117-121. https://doi.org/10.1098/rsbl.2008.0397.

Jiang, Y. J., Brand, M., Heisenberg, C. P., Beuchle, D., Furutani-Seiki, M., \& KelshRN, et al. (1996). Mutations affecting neurogenesis and brain morphology in the zebrafish, Danio rerio. Development, 123, 205-216.

Jeong, J. Y., Kwon, H. B., Ahn, J. C., Kang, D., Kwon, S. H., Park, J. A., \& Kim, K. W. (2008). Functional and developmental analysis of the blood-brain barrier in zebrafish. Brain Research Bulletin, 75(5), 619-628. https://doi.org/10.1016/j. brainresbull.2007.10.043.

Kalueff, A. V., Gebhardt, M., Stewart, A. M., Cachat, J. M., Brimmer, M., Chawla, J. S., ... Schneider, H. (2013). Towards a comprehensive catalog of zebrafish behavior 1.0 and beyond. Zebrafish, 10, 70-86. https://doi.org/10.1089/zeb. 2012.0861

Kalueff, A. V., Stewart, A. M., \& Gerlai, R. (2014). Zebrafish as an emerging model for studying complex brain disorders. Trends in Pharmacological Sciences, 35(2), 63-75. https://doi.org/10.1016/j.tips.2013.12.002.

Kawai, H., Arata, N., \& Nakayasu, H. (2001). Three-dimensional distribution of astrocytes in zebrafish spinal cord. Glia, 36, 406-413.

Kimmel, C. B., Patterson, J., \& Kimmel, R. O. (1974). The development and behavioral characteristics of the startle response in the zebrafish. Developmental Psychobiology, 7, 47-60. https://doi.org/10.1002/dev.420070109.

Kimmel, C. B., Warga, R. M., \& Schilling, T. F. (1990). Origin and organization of the zebrafish fate map. Development, 108, 581-594.

Lam, C. S., Marz, M., \& Strahle, U. (2009). Gfap and nestin reporter lines reveal characteristics of neu-ral progenitors in the adult zebrafish brain. Developmental Dynamics, 238, 475-486. https://doi.org/10.1002/dvdy.21853.

Levin, E. D., Bencan, Z., \& Cerutti, D. T. (2007). Anxiolytic effects of nicotine in zebrafish. Physiology \& Behavior, 90, 54-58. https://doi.org/10.1016/j.physbeh. 2006.08.026.

Meshalkina, D. A., Kizlyk, M. N., Kysil, E. V., Collier, A. D., Echevarria, D. J., Abreu, M. S., ... Kalueff, A. V. (2017). Zebrafish models of autism spectrum disorder. Experimental Neurology. https://doi.org/10.1016/j.expneurol.2017.02.004.

Miller, N. Y., \& Gerlai, R. (2011). Shoaling in zebrafish: What we don't know. Reviews in the Neurosciences, 22, 17-25. https://doi.org/10.1515/RNS.2011.004.

Mueller, T., Vernier, P., \& Wullimann, M. F. (2004). The adult central nervous cholinergic system of a neurogenetic model animal, the zebrafishDanio rerio. Brain Research, 1011, 156-169. https://doi.org/10.1016/j.brainres.2004.02.073.

Norton WH. (2013). Toward developmental models of psychiatric disorders in zebrafish. Neural Circuits. doi.org/https://doi.org/10.3389/fncir.2013.00079

Norton W, Bally-Cuif L. (2010). Adult zebrafish as a model organism for behavioural genetics. BMC Neuroscience.

Panula, P., Sallinen, V., Sundvik, M., Kolehmainen, J., Torkko, V., Tiittula, A., et al. (2006). Modulatory neurotransmitter systems and behavior: Towards zebrafish models of neurodegenerative diseases. Zebrafish, 3, 235-247. https://doi.org/ 10.1089/zeb.2006.3.235.

Raible, D. W., Wood, A., Hodsdon, W., Henion, P. D., Weston, J. A., \& Eisen, J. S. (1992). Segregation and early dispersal of neural crest cells in the embryonic zebrafish. Developmental Dynamics, 195, 29-42. https://doi.org/10.1002/aja. 1001950104

Shin, J. T., \& Fishman, M. C. (2002). From zebrafish to human: Modular medical models. Annual Review of Genomics and Human Genetics, 3, 311-340. https:// doi.org/10.1146/annurev.genom.3.031402.131506.

Sisson, M., \& Gerlai, R. (2010). Associative learning in zebrafish (Danio rerio) in the plus maze. Behavioural Brain Research, 207(1), 99-104. https://doi.org/10.1016/ j.bbr.2009.09.043. 
Stewart, A. M., Ullmann, J. F., Norton, W. H., Parker, M. O., Brennan, C. H., Gerlai, R., \& Kalueff, A. V. (2014). Molecular psychiatry of zebrafish. Mol. Psychiatry, 20(1), 2-17. https://doi.org/10.1038/mp.2014.128.

Tropepe, V., \& Sive, H. L. (2003). Can zebrafish be used as a model to study the neurodevelopmental causes of autism? Genes, Brain, and Behavior, 2, 268-281.

Way, G. P., Ruhl, N., Snekser, J. L., Kiesel, A. L., \& McRobert, S. P. (2015). A

comparison of methodologies to test aggression in zebrafish. Zebrafish, 12, 144-151. https://doi.org/10.1089/zeb.2014.1025.

Wilson, S. W., Ross, L. S., Parrett, T., \& Easter Jr., S. S. (1990). The development of a simple scaffold of axon tracts in the brain of the embryonic zebrafish, Brachy Danio rerio. Development, 108, 121-145.

Wolman, M. A., Jain, R. A., Liss, L., \& Granato, M. (2011). Chemical modulation of memory formation in larval zebrafish. Proceedings of the National Academy of Sciences of the United States of America, 108, 15468-15473. https://doi.org/10. 1073/pnas.1107156108.

Zakaria ZZ, Benslimane FM, Nasrallah GK, Shurbaji S, Younes NN, Mraiche F, Da'as SI, Yalcin HC. (2018). Using zebrafish for investigating the molecular mechanism of drug induced cardiotoxicity. Hindawi BioMed Research International. doi:org/https://doi.org/10.1155/2018/1642684

\section{Publisher's Note}

Springer Nature remains neutral with regard to jurisdictional claims in published maps and institutional affiliations.

\section{Submit your manuscript to a SpringerOpen ${ }^{\circ}$ journal and benefit from:}

- Convenient online submission

- Rigorous peer review

- Open access: articles freely available online

High visibility within the field

- Retaining the copyright to your article

Submit your next manuscript at $\boldsymbol{\nabla}$ springeropen.com 